\title{
A comparative study of plant water extraction methods for isotopic analyses: Scholander-type pressure chamber vs. cryogenic vacuum distillation
}

Giulia Zuecco ${ }^{1}$, Anam Amin ${ }^{1}$, Jay Frentress ${ }^{2}$, Michael Engel ${ }^{2}$, Chiara Marchina ${ }^{1}$, Tommaso Anfodillo ${ }^{1}$, Marco Borga ${ }^{1}$, Vinicio Carraro ${ }^{1}$, Francesca Scandellari ${ }^{3}$, Massimo Tagliavini ${ }^{2}$, Damiano Zanotelli $^{2}$, Francesco Comiti ${ }^{2}$, and Daniele Penna ${ }^{4}$

${ }^{1}$ Department of Land, Environment, Agriculture and Forestry, University of Padova, Italy

${ }^{2}$ Faculty of Science and Technology, Free University of Bozen-Bolzano, Italy

${ }^{3}$ Isotracer s.r.l., Bologna, Italy

${ }^{4}$ Department of Agriculture, Food, Environment and Forestry, University of Florence, Italy

Correspondence: Giulia Zuecco (giulia.zuecco@unipd.it)

\begin{abstract}
.
Recent tracer-based studies using stable isotopes of hydrogen and oxygen showed that different methods for extracting water from plant tissues can return different isotopic composition due to the presence of organic compounds and the extraction of different plant water pools. One of the most used methods to extract plant water is the cryogenic vacuum distillation (CVD), which tends to extract total plant water. Conversely, the Scholander-type pressure chamber (SPC), which is commonly used by tree physiologists to measure shoot water potential and determine plant water stress, has been rarely applied to extract plant water for isotopic analyses.

In this work, we analyzed the variability in the isotopic composition of plant water extracted by SPC and CVD, also considering the potential variability in the isotopic signature of the plant tissues (i.e., leaves, twig without bark, twig with bark, twig close to the trunk of the tree, and wood core) and plant species (i.e., alder, apple, chestnut and beech). The extraction of plant water by SPC is simple, can be carried out in situ, and it does not require specific laboratory work as in case of CVD. However, the main limitation of SPC is the very small water volume that can be extracted from the lignified shoots during conditions of water deficit, compared to CVD.

Our results indicated that plant water extracted by SPC and CVD were significantly different. The difference in the isotopic composition obtained by the two extraction methods was smaller in the beech samples compared to alder, apple and chestnut samples. The isotopic signature of alder, apple and chestnut plant water extracted by SPC was more enriched in $\delta^{2} \mathrm{H}$ and $\delta^{18} \mathrm{O}$, respectively, than the samples obtained by CVD. We conclude that plant water extraction by SPC is not an alternative for CVD, as SPC likely extracts only water within the xylem (dead cells), whereas CVD tends to retrieve all water stored in the sampled tissue, from both living and dead cells. However, studies aiming to quantify the relative contribution of the water sources to transpiration should rely more on the isotopic composition of xylem water transpiring during the sampling day (which is theoretically sampled by SPC), than the isotopic composition of total plant water (sampled by CVD), which also contains a fraction of water that could be stored in plant tissues for long time.
\end{abstract}


Keywords: stable isotopes of hydrogen and oxygen; cryogenic vacuum distillation; Scholander-type pressure chamber; plant water; xylem water.

\section{Introduction}

Stable isotopes in the water molecule $\left({ }^{2} \mathrm{H}\right.$ and $\left.{ }^{18} \mathrm{O}\right)$ have been extensively used as environmental tracers in atmospheric and hydrological studies to track water movement, estimate mean residence times and water storage (e.g., Dansgaard, 1953; Craig, 1961; Klaus and McDonnell, 2013). The development of low-cost and easy-to-use spectroscopic techniques for the collection and isotopic analysis of water samples at a high temporal resolution (e.g., Kerstel et al., 1999; Penna et al., 2010; von Freyberg et al., 2017) stimulated the application of stable isotopes to investigate the water fluxes in the soil-plant-atmosphere continuum (Brooks et al., 2010; McDonnell, 2014). An increasing number of new studies has been conducted to better understand water dynamics, such as water uptake and evapotranspiration partitioning, in the soil-plant-low atmosphere continuum in different climates and in both natural (e.g., Allen et al., 2019; Dubbert et al., 2019; Liu et al., 2019a; Oerter et al., 2019; Qiu et al., 2019) and managed (agricultural and agroforest) (e.g., Liu et al., 2019b; Quade et al., 2019; Zhang et al., 2019; Penna et al., 2020) environments. Compared to the rapid increase of the number of studies using a stable isotope approach, only a small fraction of them focused on the comparison of two or more soil or plant water extraction techniques (Sprenger et al., 2015; Orlowski et al., 2016b; Millar et al., 2018; Fischer et al., 2019).

Ecohydrological studies relying on the isotopic signature of plant water require sampling methods that do not alter the true isotopic composition of the plant material, which is still a critical issue because a standardized and shared procedure and method has not been developed yet (Penna et al., 2018). Indeed, there is a variety of different techniques for the extraction of plant water, such as in situ direct vapour equilibration (Sprenger et al., 2015; Volkmann et al., 2016), microwave extraction (Munksgaard et al., 2014), cryogenic vacuum distillation (Koeniger et al., 2011; Orlowski et al., 2013, 2016a), centrifugation (Peters and Yakir, 2008), and high-pressure mechanical squeezing (Böttcher et al., 1997). Among these, cryogenic vacuum distillation (abbreviated in CVD thereinafter) is widely applied (Orlowski et al., 2018; Amin et al., 2020). This technique extracts the entire volume of water from plant tissues, which may include water stored in dead and living cells for months or years, so not only water that is being transported at the time of sampling. This might be a serious limitation in ecohydrological and physiological studies aiming at understanding water sources for plant transpiration. Different techniques might return different isotopic values because of intrinsic methodological differences. This is also the case of CVD that, for examples, provides a large variability of results in case of soil water extraction (Orlowski et al., 2018). Indeed, the inter-laboratory comparison of the cryogenic water extraction systems carried out by Orlowski et al. (2018) showed that there were large differences in the isotopic composition of the extracted soil water among different laboratories, although the same procedure, soil, and labelling water was used. The authors also observed no clear trends in the results due to construction systems and applied extraction conditions, but differences depended on the interaction of multiple factors, such as soil type and properties, soil water content, system setup, extraction efficiency, extraction system leaks, and each lab's internal accuracy. 

who performed an inter-method comparison of six plant water extraction techniques (i.e., direct vapor equilibration, microwave extraction, two versions of CVD, centrifugation and high-pressure mechanical squeezing) tested on four plant portions of spring wheat (Triticum aestivum). The authors found marked differences among the measured isotopic compositions of the plant water, with the CVD systems and the high-pressure mechanical squeezing producing waters more depleted in heavy isotopes. Millar et al. (2018) concluded that, in terms of limited co-extraction of organic compounds and speed of sample throughput, the direct vapor equilibration outperformed CVD. Fischer et al. (2019) proposed various low-tech plant water sampling and extraction techniques and compared them to the widely-used CVD developed by Koeniger et al. (2011). These authors developed six simple and low-cost methods to extract plant water and compared them to CVD. They found that the new methods extracted plant water consistently and comparably to what was done with CVD. Fischer et al. (2019) also showed that other factors, such as appropriate transport and storage of the samples from the field site to the laboratory, fast sample processing and efficient workflows significantly influenced the accuracy and precision of the measured isotopic composition.

Despite the increasing number of studies focusing on inter-laboratory and inter-method comparison of techniques for plant water extraction, previous research did not consider ecophysiological-based methods that tree physiologists usually adopt to measure leaf water potential and determine plant water stress (e.g., Meiri et al., 1975; Grossiord et al., 2017; Bowling et al., 2017). One of these methods, i.e. the Scholander-type pressure chamber (abbreviated in SPC thereinafter) takes advantage of an external pressure to retrieve the water transported within the xylem conduits to measure the shoot water potential. Despite that SPC is widely-used in plant water relations studies, it seems that it is not commonly applied to collect the extracted water for isotopic analyses. So far, we have found only two studies (i.e., Penna et al., 2013; Gei $\beta$ ler et al., 2019) reporting the isotopic composition of plant water extracted by SPC. Of the two studies, Gei $\beta$ ler et al. (2019) made a simple comparison between $\delta^{18} \mathrm{O}$ of water extracted by SPC and CVD in six stem water samples collected from Acacia mellifera shrubs, and found no difference in the isotopic composition of the plant water extracted by the two methods. However, despite this first basic comparison made by Geißler et al. (2019), no other robust attempts were made to compare SPC with the widely-used CVD extraction technique.

Therefore, in this study we compare the isotopic composition of plant water extracted by SPC and CVD (considered here as the reference method). Specifically, our research aims to: $i$ ) quantify the differences in the isotopic composition of plant water extracted by the two techniques, $\mathrm{ii}$ ) assess how differences in the isotopic composition are related to plant species or plant tissue type used for CVD.

\section{Study sites and sampling}

\subsection{Ahr/Aurino}

Samples from grey alder trees (Alnus incana) were taken in the riparian area of the Ahr/Aurino River in the Eastern Italian Alps (Fig. 1). The study site is located at about $882 \mathrm{~m}$ a.s.1. in the lower valley, where the typical valley form is U-shape. The basin is mostly composed of metamorphic (gneiss, micaschists) and magmatic (tonalite) rocks. The climate is cold temperate with an average annual air temperature of about $7.7^{\circ} \mathrm{C}(1992-2018)$ and an average yearly precipitation amount of about $821 \mathrm{~mm} / \mathrm{yr}$ 
(1972-2018) (Autonomous Province of Bozen-Bolzano). The Ahr/Aurino River regime is nivo-glacial (glacierized area is about 4\%). Riparian vegetation mainly consists of relatively mature patches of grey alder with a thick tall herb (Rubus caesius, Glechoma hederacea and Urtica dioica, Sambucus nigra shrubs and the vine Humulus lupulus). Gravel mining activities in the 1950s to the 1980s resulted in riverbed incision, and a floodplain being disconnected from its channel (Campana et al., 2014).

The sampling campaign was carried out on 7 June 2017 during a period of prolongated water deficit. Samples for plant water extraction were collected after the sunset from four alder trees at the downstream in the Ahr/Aurino study area. The selected alder trees were located within few meters to each other to avoid high spatial variability in the isotopic composition of plant water.
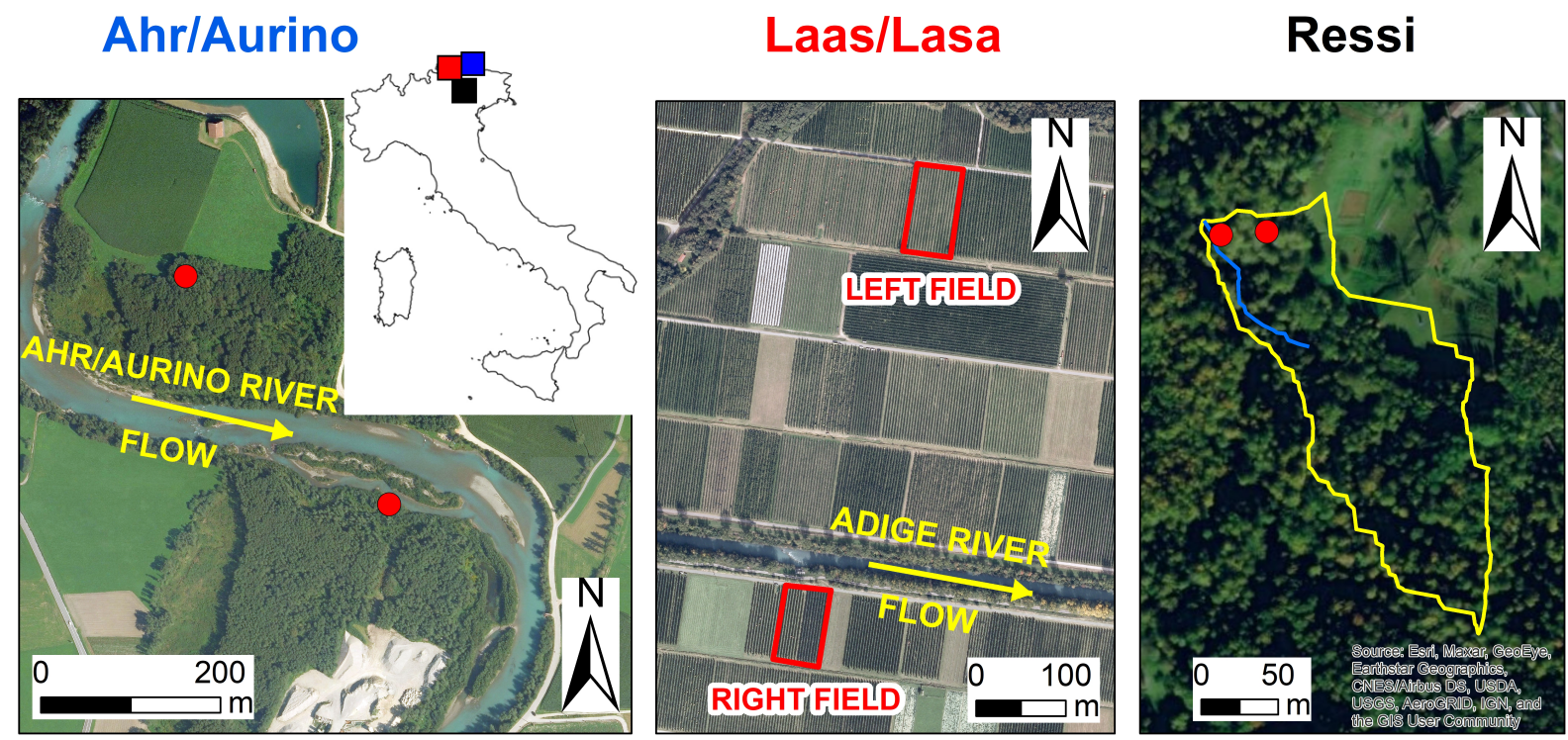

Figure 1. Aerial photos of the study sites, and location in northern Italy (blue: Ahr/Aurino; red: Laas/Lasa; black: Ressi). Red dots in Ahr/Aurino and Ressi indicate the approximate position of the sampled trees. In Ressi, the blue and the yellow solid lines mark the stream network and the catchment divide, respectively. Sources of aerial photos: CAutonomous Province of Bolzano-South Tyrol (study sites: Ahr/Aurino and Lasa); Esri, "World Imagery" [basemap], scale not given, "World Imagery", August 14, 2020, http://www.arcgis.com/home/item.html?id=10df2279f9684e4a9f6a7f08febac2a9, (September 1, 2020) (study site: Ressi). The maps were made using Esri ArcGIS 10.7.1.

\subsection{Laas/Lasa}

Samples from cultivated apple trees (Malus domestica, cv. "Pinova" grafted on "M9" rootstock) were collected in two apple orchards in the Laas/Lasa (Vinschgau/Val Venosta region, South Tyrol; Fig. 1). The orchards are located at about $800 \mathrm{~m}$ a.s.l. on the right and left side of the river Etsch/Adige, with different distance from the river ( $50 \mathrm{~m}$ vs. $450 \mathrm{~m}$, respectively). Within each orchard, a plot of about $400 \mathrm{~m}^{2}$ was selected for sampling. The average annual air temperature is about year $9{ }^{\circ} \mathrm{C}$ and 
Table 1. Sample size and median isotopic composition of the samples extracted by Scholander-type pressure chamber (SPC) and cryogenic vacuum distillation (CVD) from different plant tissues (L: leaves; T: twig without bark; TwB: twig with bark; WC: wood core; TcT: twig close to the trunk) and species in the three study sites (Ahr/Aurino, Laas/Lasa and Ressi).

\begin{tabular}{|c|c|c|c|c|}
\hline Plant species & Sample type & Sample size & Median $\delta^{2} \mathbf{H}(\%)$ & Median $\delta^{18} \mathbf{O}(\% o)$ \\
\hline \multirow{5}{*}{$\begin{array}{l}\text { Alder (study site: } \\
\text { Ahr/Aurino) }\end{array}$} & SPC & 4 & -37.8 & -4.95 \\
\hline & CVD-L & 4 & -7.6 & 8.99 \\
\hline & CVD-T & 4 & -53.7 & -6.51 \\
\hline & CVD-TwB & 4 & -80.7 & -7.37 \\
\hline & CVD-WC & 4 & -49.4 & -6.86 \\
\hline \multirow{5}{*}{$\begin{array}{l}\text { Apple (study } \\
\text { site: Laas/Lasa) }\end{array}$} & $\mathrm{SPC}$ & 8 & -63.8 & -8.91 \\
\hline & CVD-L & 8 & -12.9 & 11.92 \\
\hline & CVD-T & 5 & -75.7 & -10.10 \\
\hline & CVD-TwB & 8 & -80.6 & -9.91 \\
\hline & CVD-WC & 5 & -85.7 & -10.52 \\
\hline \multirow{5}{*}{$\begin{array}{l}\text { Chestnut (study } \\
\text { site: Ressi) }\end{array}$} & SPC & 4 & -14.2 & -3.55 \\
\hline & CVD-L & 4 & 8.8 & 5.76 \\
\hline & CVD-T & 4 & -30.6 & -5.69 \\
\hline & CVD-TwB & 2 & -26.9 & -4.48 \\
\hline & CVD-TcT & 4 & -35.4 & -5.74 \\
\hline \multirow{5}{*}{$\begin{array}{l}\text { Beech (study } \\
\text { site: Ressi) }\end{array}$} & SPC & 3 & -24.8 & -5.75 \\
\hline & CVD-L & $3\left(1\right.$ for $\left.\delta^{2} H\right)$ & 7.5 & 4.87 \\
\hline & CVD-T & $3\left(2\right.$ for $\left.\delta^{2} H\right)$ & -22.2 & -5.65 \\
\hline & CVD-TwB & 3 & -32.8 & -5.74 \\
\hline & CVD-TcT & 3 & -33.1 & -5.64 \\
\hline
\end{tabular}

the average yearly precipitation amounts about $512 \mathrm{~mm} / \mathrm{yr}$ (2009-2018) (Autonomous Province of Bozen-Bolzano). The soil in both orchards had a silty loam texture.

The sampling campaign was performed on 8 June 2017 during a period of water deficit. All samples were equally taken both at the right and the left field, after the sunset.

\subsection{Ressi}

Samples from beech (Fagus sylvatica) and chestnut (Castanea sativa) trees were collected in the 2.4-ha Ressi catchment in the Italian pre-Alps (Fig. 1) (Penna et al., 2013; Zuecco et al., 2014; Penna et al., 2015; Zuecco et al., 2016). The catchment is located at the foothills of the eastern Italian Alps (elevation range: 598-721 m a.s.1.) and is densely vegetated. The climate is humid temperate and the average annual precipitation (1992-2007) recorded by a weather station approximately $4.5 \mathrm{~km}$ from 
Ressi is $1695 \mathrm{~mm} / \mathrm{yr}$ (Penna et al., 2015). Monthly distribution of rainfall is bimodal with peaks in spring and fall. The mean annual temperature is $9.7^{\circ} \mathrm{C}$; on average the minimum monthly temperature is in January $\left(1.2^{\circ} \mathrm{C}\right)$ and the maximum in July $\left(18.7^{\circ} \mathrm{C}\right)$.

The sampling campaign was carried out on 5 July 2017 during a period of prolongated water deficit. Samples for plant water extraction were retrieved at the sunrise from five beech and five chestnut trees in the lower part of the Ressi catchment.

The sampling design aimed to replicate the sample collection in all the selected trees with the two investigated methodologies (Table 1). However, plant water extraction was not always possible by the SPC method because, in some cases (1 out of 5 chestnut samples, and 2 out of 5 beech samples), the extracted plant water volume was not always enough for isotopic analysis. In addition, we discarded some plant water samples extracted by CVD, affected by bad injections, and for which we could not perform a second run of isotopic analyses due to the small water volume. Therefore, in this study we reported only the isotopic data relative to the plant water extracted by both methods (i.e., SPC and CVD) from the same trees (Table 1).

\section{Materials and methods}

\subsection{Extraction of plant water: the SPC method}

The SPC is an instrument normally used by tree physiologists to measure shoot water potential (e.g., Meiri et al., 1975; Donovan et al., 2003; Grossiord et al., 2017). Typically, SPC is used to determine plant water potential (Cochard et al., 2001) and, being a proxy of the tissue water content, it can signal the occurrence of water deficit. The basic working principle is the use of an external pressure to retrieve the water within the xylem conduits (Scholander et al., 1965; Turner, 1981; Castro Neto et al., 2004) (Fig. 2). In this study, we used the SPC to force water out of the xylem tissues, and collect water samples for isotopic analyses.

The SPC contains a cutting board used to prepare the sample, i.e. one-year old suberized shoots. The set up consisted of one or more leaves sealed inside the chamber, while the cut end of the suberized shoot was exposed to the atmosphere (Fig. 2). After connecting the SPC to the gas tank, a three-way control valve was turned to pressure and the metering valve was slowly opened to begin to pressurize the unit. A pressure equal to shoot water potential was applied until water sprang from the cut end of the one-year old shoot. For the SPC plant water extractions, we used a Pump-Up Chamber with a 2.0 MPa gauge (PMS Instrument Company, Oregon, USA) in Ahr/Aurino and Laas/Lasa, and a SAPS II portable plant water status console (model 3115) with a 4.0 MPa gauge (Soilmoisture Equipment Corp., California, USA) in Ressi. The xylem water was collected directly (or by using pipettes) in $2 \mathrm{ml}$ glass vials, which were immediately capped. To extract water from the plant tissues, we had to apply a pressure of about 0.5 MPa in Laas/Lasa, 1.0-1.5 MPa in Ahr/Aurino, and 3.0 MPa in Ressi; the different shoot water potentials indicate that the sampled vegetation in Ressi suffered higher water deficit conditions than the sampled plants in Ahr/Aurino and Laas/Lasa. The water extraction by the SPC method ended when we collected all the water flowing out from the shoots. Note that the sampled volume was smaller than $2 \mathrm{ml}$ during the sampling campaigns carried out for this study. All the samples were stored in a fridge at $4{ }^{\circ} \mathrm{C}$ until the isotopic analyses. 


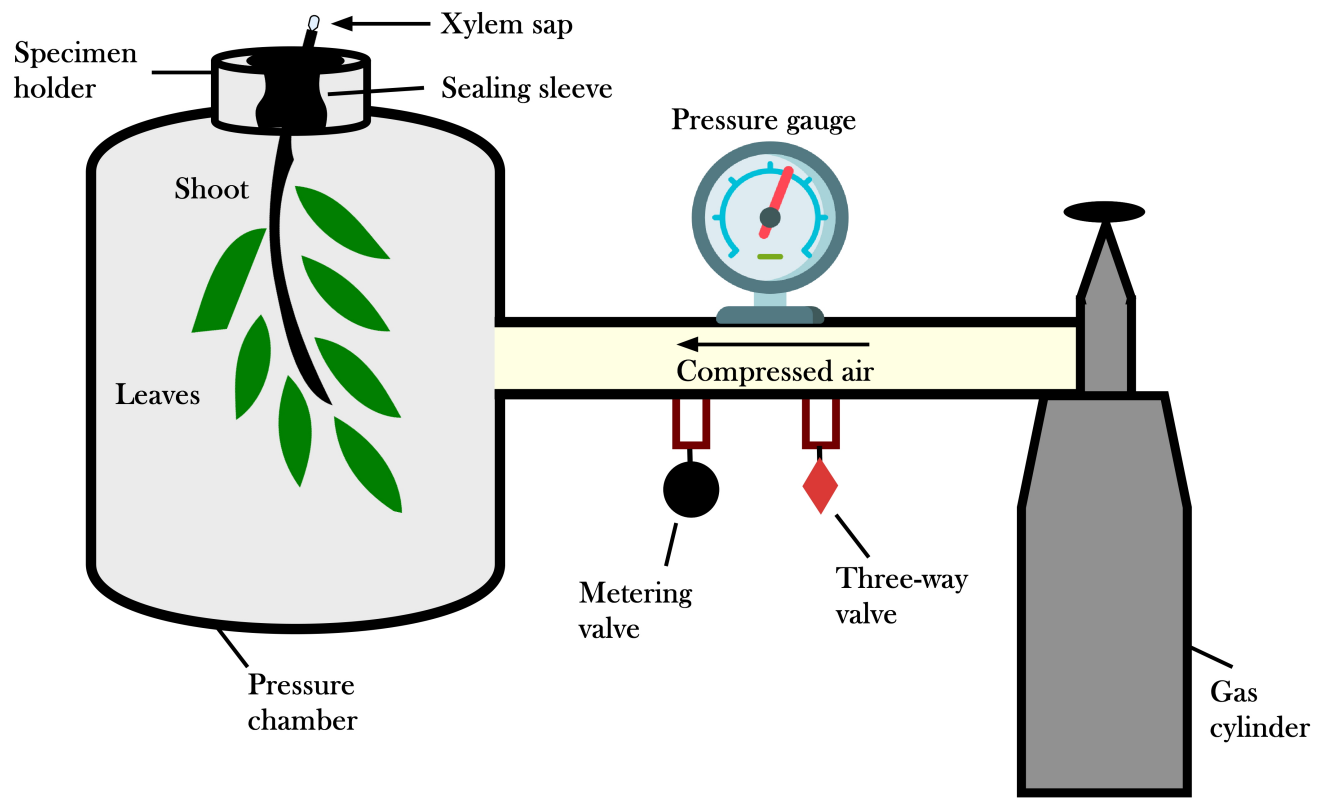

Figure 2. Sketch showing the technical setup of the Scholander-type pressure chamber (SPC).

\subsection{Extraction of plant water: the CVD method}

To extract plant water by CVD, we collected samples from different plant tissues, along a branch, in $12 \mathrm{ml}$ glass Exetainer® vials (Labco Ltd., UK). After cutting the twigs from the trees, we removed all the leaves and other green tissues close to the leaves. Some of these leaves were collected in the vials for the extraction by CVD (i.e., CVD-L samples). The twig samples were lignified and approximately $85 \mathrm{~mm}$ long and 3-6 mm thick. For some of the twig samples, we kept the bark (i.e., twig with bark samples, abbreviated in CVD-TwB), whereas for others, bark was peeled using a knife (i.e., twig without bark samples, abbreviated in CVD-T; Table 1). Samples with and without bark were used to test whether the plant water extracted by the SPC method had an isotopic composition more similar to CVD-extracted bulk plant water (i.e., CVD-TwB) or to plant water deprived of phloem tissues (i.e., CVD-T). In Ahr/Aurino and Laas/Lasa study sites, the diameters at the breast height of the alder and apple trees allowed for the collection of wood core samples (abbreviated in CVD-WC), that were retrieved by an increment borer. In Ressi, instead of wood cores, we collected additional twig samples that were located close to the trunk (abbreviated in CVD-TcT). For these samples, we removed the bark by a knife. CVD-TcT samples were supposed to have older tissues and more dead cells than the twigs collected closer to the leaves (i.e., CVD-T and CVD-TwB). All the samples for CVD were stored in a fridge at $4{ }^{\circ} \mathrm{C}$ until the extraction and the consequent isotopic analyses.

The CVD was performed in the laboratory of the Faculty of Science and Technology of the Free University of BozenBolzano (Italy) (Fig. 3). The CVD system was developed based on the method of Koeniger et al. (2011). The system consists 
of independent extraction-collection units where the capped sample vial was connected to a second empty vial (hereafter collection vial) using a $1.56 \mathrm{~mm}$ diameter stainless steel capillary tube. After the preparation of the extraction-collection unit, the samples were frozen by immersing the sample vials in liquid nitrogen (approximately at $-196{ }^{\circ} \mathrm{C}$ ) to prevent loss of water vapor during evacuation (vials were evacuated to a pressure of $0.95 \mathrm{kPa}$ ). The sample vials were then loaded in an aluminum block (with slots for 10 vials) and heated to a temperature of $200{ }^{\circ} \mathrm{C}$ (Fig. 3). At the same time, during the extraction process, the bottom of the collection vials was immersed into the liquid nitrogen trap, which allowed for the evacuation of the sample from the heated vial and its condensation in the collection vial. All the individual plant samples were extracted at a temperature of $200{ }^{\circ} \mathrm{C}$ for an extraction time of 15 min per sample. A heat gun (at $300{ }^{\circ} \mathrm{C}$ ) was used at the end of each extraction round to remove from the steel tube any water vapor trapped in the capillary tube. After the water had been quantitatively transferred from the plant tissue to the collection vial, vials were removed from the liquid nitrogen cold trap, defrosted at room temperature under perfect sealed conditions and stored in a refrigerator after labelling and tightly wrapped with Parafilm® until the isotopic analysis. The exhausted vials were successively recovered in $100{ }^{\circ} \mathrm{C}$ oven for 24 hours, while the capillary tubes were cleaned by acetone and then dried. All the plant samples were weighted before and after water extraction, and after the oven-drying at $100{ }^{\circ} \mathrm{C}$ for 24 hours to determine the extraction efficiency.

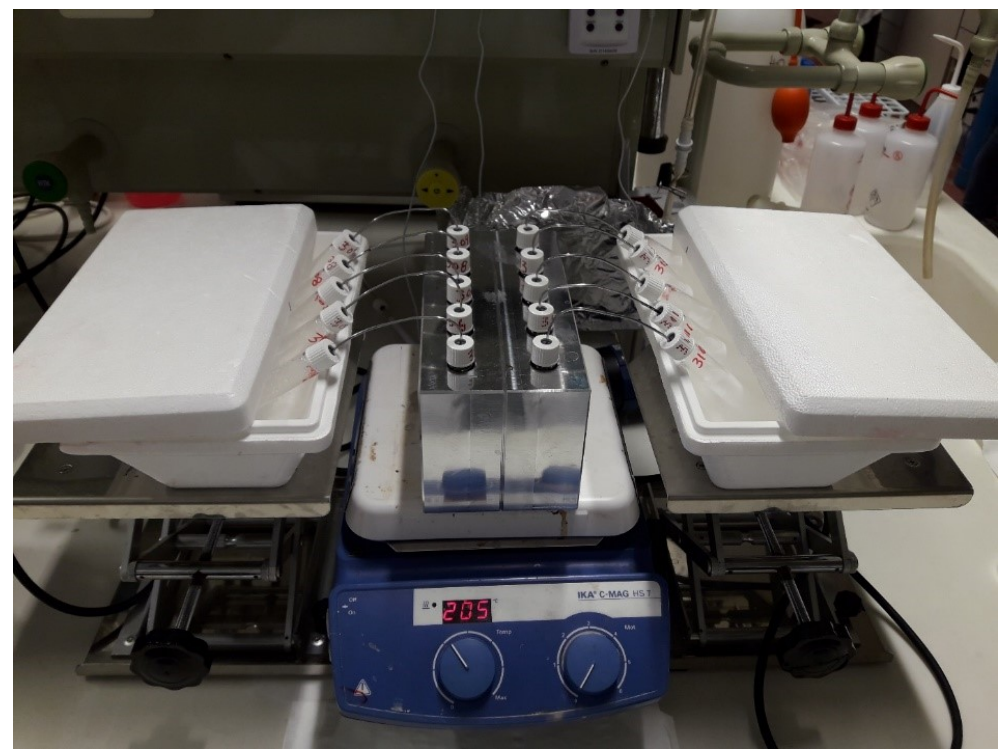

Figure 3. The cryogenic vacuum distillation (CVD) system at the Faculty of Science and Technology of the Free University of BozenBolzano, based on the method developed by Koeniger et al. (2011). 


\subsection{Isotopic analysis}

Isotopic analyses were performed by isotope-ratio mass spectrometry (IRMS) at the Faculty of Science and Technology of the Free University of Bozen-Bolzano. All water samples were analyzed using an IRMS (Delta V Advantage Conflo IV, Thermo

Fisher Scientific Inc., Waltham, Massachusetts, USA), coupled with a Thermo Scientific Gas Bench II to determine $\delta^{18}$ O.

For $\delta^{18} \mathrm{O}$, water samples were placed in Exetainer® vials and the headspace flushed by a $0.3 \% \mathrm{CO}^{2}-\mathrm{He}^{\circledR}$ gas mixture of known isotopic composition. After an equilibration phase of 24 hours, the headspace vapor phase was injected 8 times.

$\delta^{2} \mathrm{H}$ was determined by direct injection of sample into the IRMS, through Thermo Scientific High Temperature Conversion Elemental Analyzer (TC/EA, Thermo Fisher Scientific Inc., Waltham, Massachusetts, USA), equipped with an autosampler (Thermo Scientific AI/AS 3000).

\subsection{Data analysis}

The isotopic values of the samples were grouped based on the extraction method (i.e., SPC and CVD) and plant species (i.e., alder, apple, chestnut, and beech trees). In addition, samples extracted by CVD were grouped based on the collected plant tissue (i.e., leaves (CVD-L), twig with bark (CVD-TwB), twig without bark (CVD-T), twig close to the trunk of the tree (CVD-TcT) and wood core (CVD-WC)). In total, we considered 24 groups of samples for data analyses.

The samples were plotted in the dual-isotope space, together with the Local Meteoric Water Lines (LMWL) of the three study areas, obtained by the ordinary least squares regression (Marchina et al., 2020), to identify potential evaporated samples. For each sample, we also computed the deuterium excess (d-excess) (Dansgaard, 1964), as follows:

$d-$ excess $=\delta^{2} H-8 \times \delta^{18} O$

We report the d-excess values, which take into account deviation from the Global Meteoric Water Line, instead of the lineconditioned excess (Lanwehr and Coplen, 2004), which accounts the deviation from the LMWL, to compare samples from the different study areas.

Scatter plots between SPC with CVD-T, CVD-TwB, CVD-TcT and CVD-WC samples were used to assess differences (overestimation or underestimation) in the isotopic values. The Friedman repeated measures analysis of variance on ranks, paired with a multiple comparison test based on the Tukey method, was used to identify possible effects of the extraction method on the isotopic composition and d-excess of plant water collected from alder and apple trees (these tests were not applied to chestnut and beech data because the paired samples were $<4$ ). The Welch two-sample t-test was used to assess whether the differences in the isotopic composition of SPC and CVD-L samples from alder and apple trees were significant (at the 0.05 level).

To evaluate the differences in the isotopic composition between SPC and CVD extracted samples, while accounting for the uncertainty in the isotopic measurements, we computed the Z-scores for each paired sample and isotope (Wassenaar et al., 2012; Orlowski et al., 2016b), as follows:

$Z-$ score $=\frac{|C V D-S P C|}{S D}$ 
where CVD is the $\delta^{2} \mathrm{H}$ or $\delta^{18} \mathrm{O}$ value of the cryogenic extracted samples, SPC is the $\delta^{2} \mathrm{H}$ or $\delta^{18} \mathrm{O}$ value of the SPC samples, and $S D$ is the typical standard deviation of the isotopic measurements performed by the IRMS (in our case, 2.5 and 0.10 for $\delta^{2} \mathrm{H}$ and $\delta^{18} \mathrm{O}$, respectively). For the CVD samples, we distinguished the various plant tissues, i.e. CVD-T, CVD-TwB, CVD-TcT and CVD-WC. Similar to Orlowski et al. (2016b), for Z-score <2, we considered the difference between the extraction methods acceptable (i.e., the observed difference can be considered equal or lower than the uncertainty in the isotopic measurements), for

$2<Z$-score $<5$, the difference was considered questionable, whereas for Z-score $>5$ the difference was defined as unacceptable.

Scatter plots, the Friedman repeated measures analysis of variance on ranks (Scheff, 2016), and the Z-score analysis were applied only to those groups of samples that were not greatly affected by evaporation (i.e., CVD-L samples were not considered). We applied the Friedman repeated measures analysis of variance on ranks, instead of analysis of variance, because the repeated samples were few and non-normally distributed. The statistical analyses and the plots were prepared using SigmaPlot, Microsoft Excel and R.

\section{Results}

\subsection{Isotopic variability across extraction methods and plant tissues}

The isotopic composition of plant water varied considerably across the different plant tissues (Table 1 and Fig. 4). We found that CVD-L samples were more enriched in heavy isotopes than all the other plant tissues samples, and they plotted to the right side of the three LMWLs, highlighting a distinct evaporation signature (Fig. 4). Plant water extracted by SPC, CVD-T, CVDTwB, CVD-WC and CVD-TcT generally plotted close to the LMWLs, except for three CVD-TwB samples from alder trees that were more depleted in heavy isotopes and plotted on the right side of the LMWL (Fig. 4a), and two samples from beech trees (one CVD-T and one CVD-TcT) that slightly plotted on the left side of the LMWL (Fig. 4c). SPC samples were more enriched in heavy isotopes than CVD-T, CVD-TwB and CVD-WC samples collected in Ahr/Aurino (Fig. 4a) and Laas/Lasa (Fig. 4b), whereas the differences between SPC and CVD samples (except for CVD-L) were less marked in Ressi, for both beech and chestnut trees (Fig. 4c). The Welch two-sample t-test, applied only to alder and apple tree samples, showed that there was a significant difference in $\delta^{2} \mathrm{H}$ and $\delta^{18} \mathrm{O}$ of SPC and CVD-L samples ( $\mathrm{p}<0.001$ for all four tests).

The relation between $\delta^{2} \mathrm{H}$ and $\delta^{18} \mathrm{O}$ of plant water extracted by SPC and CVD showed differences among plant tissues and the four species (Fig. 5 and 6). Indeed, we observed that most of the samples did not plot on the 1:1 line, and there were very large differences between $\delta^{2} \mathrm{H}$ of SPC and CVD-TwB, particularly for alder tree samples (the absolute differences varied between 16.1 and $48.9 \%$ ) and apple tree samples (the absolute differences varied between 12.0 and $21.7 \%$ ) (Fig. 5). For alder, apple and chestnut tree samples, we found that $\delta^{2} \mathrm{H}$ of SPC was always more positive than $\delta^{2} \mathrm{H}$ of CVD samples. The $\delta^{2} \mathrm{H}$ of plant water collected from beech trees by CVD-T, CVD-TwB and CVD-TcT was not systematically more enriched or depleted than $\delta^{2} \mathrm{H}$ that of SPC samples.

Likewise, we found differences in $\delta^{18} \mathrm{O}$ values between SPC and CVD samples (Fig. 6). However, compared to $\delta^{2} \mathrm{H}$, more samples plotted closer to the 1:1 line. The differences between SPC with CVD-T and CVD-TwB of beech samples were small (the median of the absolute differences was $0.22 \%, \mathrm{n}=6$ ), and the samples plotted very close to the 1:1 line (Fig. 6). SPC 

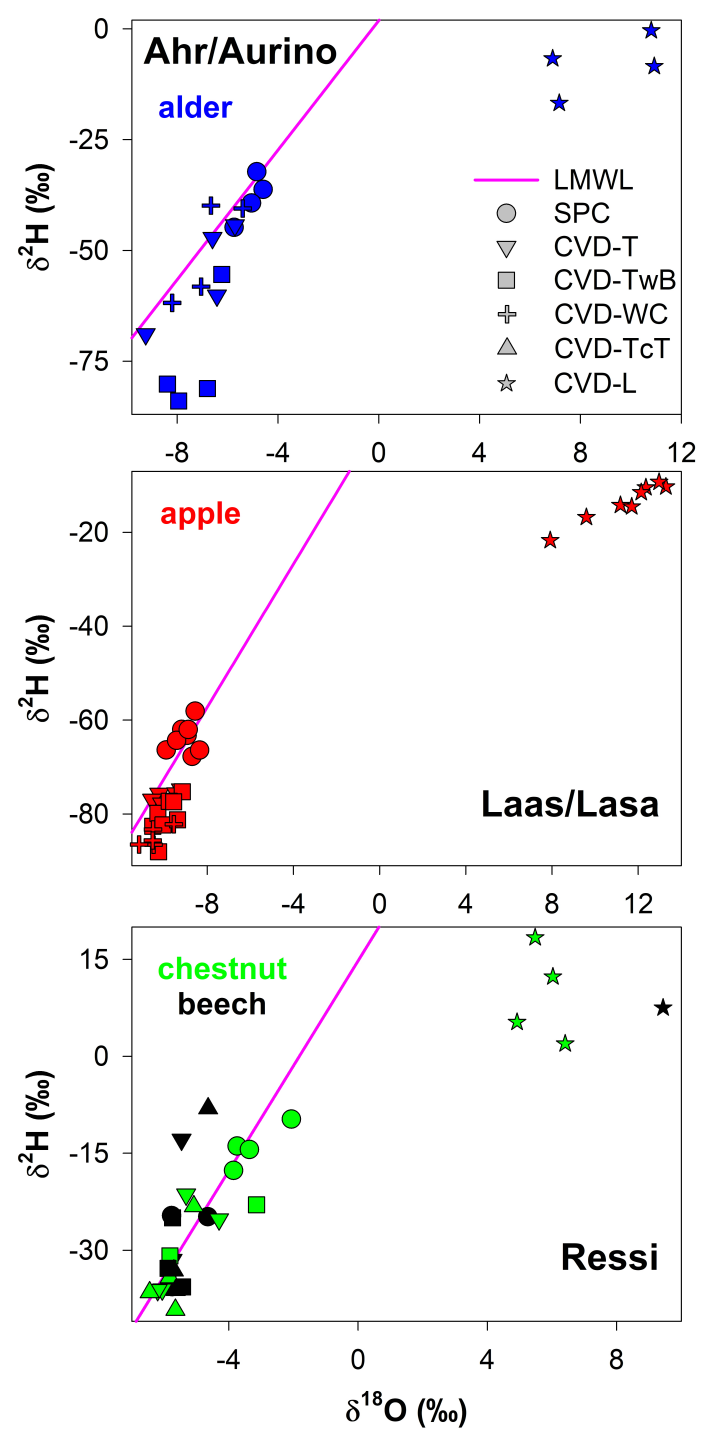

Figure 4. Dual-isotope plot for plant water samples extracted by Scholander-type pressure chamber (SPC), and cryogenic vacuum distillation (CVD) for different plant tissues (CVD-T, CVD-TwB, CVD-WC, CVD-TcT and CVD-L indicate samples extracted by CVD from twig without bark, twig with bark, wood core, twig close to the trunk of the tree and leaves, respectively) and species (alder, apple, chestnut and beech). Local Meteoric Water Lines (LMWL) are also plotted in pink: Ahr/Aurino: $\delta^{2} H=7.31 \times \delta^{18} O+1.89$ (Engel et al., in review), Laas/Lasa: $\delta^{2} H=7.62 \times \delta^{18} O+3.67$ (unpublished data), Ressi: $\delta^{2} H=8.12 \times \delta^{18} O+14.75$ (Marchina et al., 2020). 
samples from alder, apple and chestnut trees were less negative in $\delta^{18} \mathrm{O}$ than CVD samples, but for apple tree samples the differences between SPC and CVD-TwB were relatively small (the median of the absolute differences was $0.57 \% 0, \mathrm{n}=8$ ).
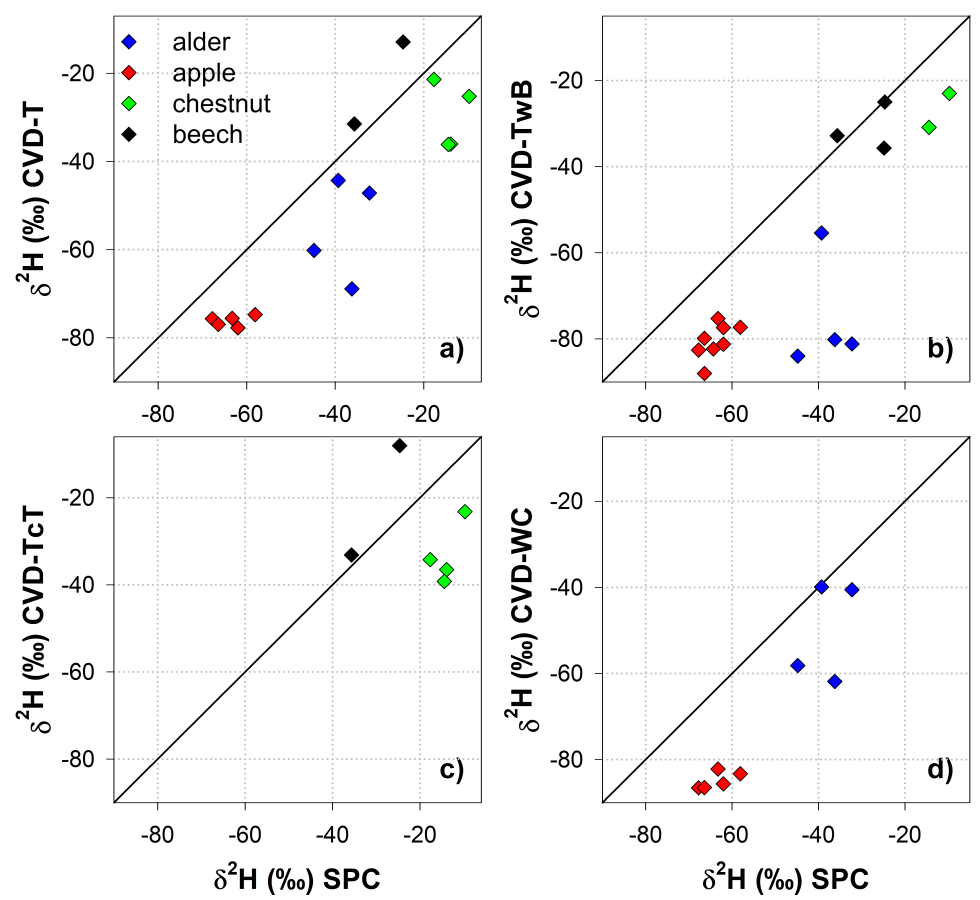

Figure 5. Relation between $\delta^{2} \mathrm{H}$ values in plant water extracted by SPC (i.e., Scholander-type pressure chamber) and CVD (i.e., cryogenic vacuum distillation), grouped by plant tissue and species. The solid black lines represent $\mathrm{y}=\mathrm{x}$.

\subsection{Effect of the extraction method on plant water isotopic composition}

The Friedman repeated measures analysis of variance on ranks (applied only on alder and apple isotopic data) showed that there was a significant effect (with $\alpha=0.05$ ) of the extraction method and plant tissue on $\delta^{2} \mathrm{H}$ and $\delta^{18} \mathrm{O}$ of plant water (Fig. 7). For alder trees, we found that SPC samples were significantly different in $\delta^{2} \mathrm{H}$ and $\delta^{18} \mathrm{O}$ from CVD-TwB samples $(\mathrm{p}<0.05$, pairs $=4$, Tukey test). For apple trees, SPC samples differed in $\delta^{2} \mathrm{H}$ and $\delta^{18} \mathrm{O}$ from CVD-WC samples $(\mathrm{p}<0.05$, pairs $=5$, Tukey test).

When considering d-excess, we observed that there was not a significant effect of the extraction method on the sample isotopic composition ( $p>0.05$, Friedman repeated measures analysis of variance on ranks). d-excess highly-varied among the various samples; values were quite large for beech tree samples, slightly less positive for chestnut tree samples, and below 8.0 or even negative for alder and apple tree samples (Fig. 7). A marked evaporation signature was found only for CVD-TwB samples collected from alder trees. 

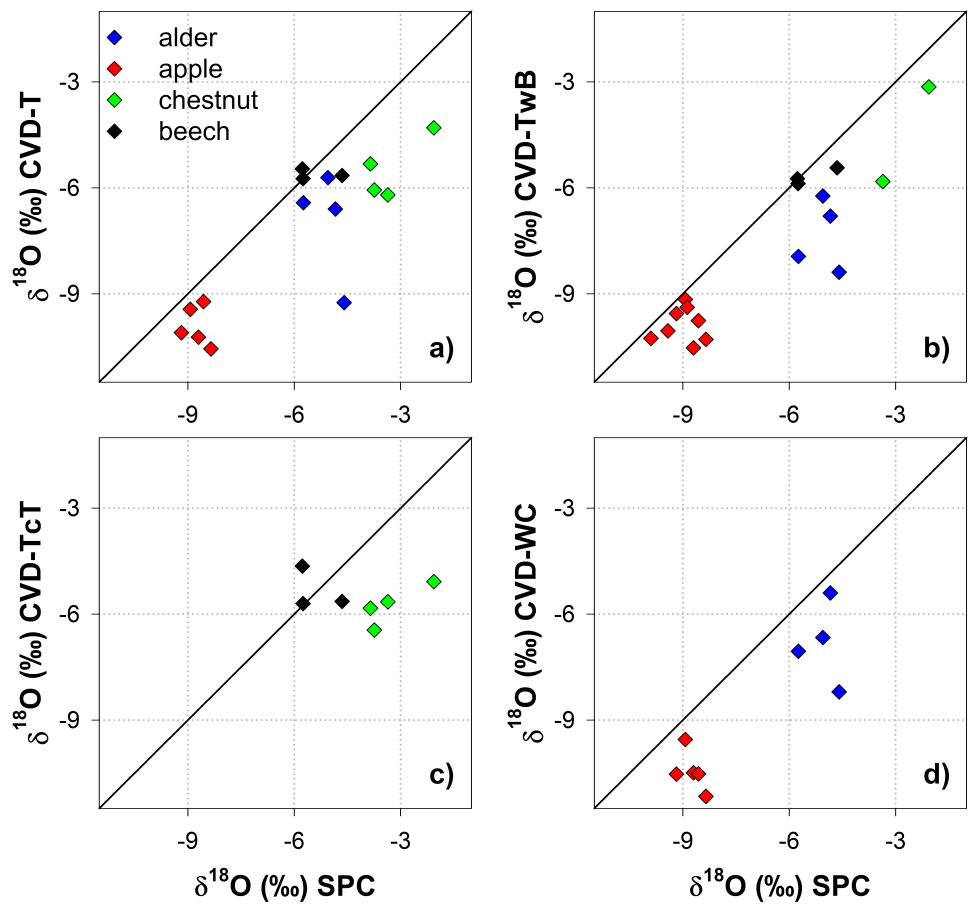

Figure 6. Relation between $\delta^{18} \mathrm{O}$ in plant water extracted by SPC (i.e., Scholander-type pressure chamber) and CVD (i.e., cryogenic vacuum distillation), grouped by plant tissue and species. The solid black lines represent $\mathrm{y}=\mathrm{x}$.

\subsection{Are the differences between SPC and CVD larger than the uncertainty in the isotopic measurements?}

The Z-score analysis showed that generally the differences between $\delta^{2} \mathrm{H}$ and $\delta^{18} \mathrm{O}$ of SPC and CVD samples were larger than the uncertainty in the isotopic measurements (Fig. 8). Due to the larger uncertainty in $\delta^{2} \mathrm{H}$ measurements compared to $\delta^{18} \mathrm{O}$ (based on the IRMS used in this study), we observed that the computed Z-scores were smaller for $\delta^{2} \mathrm{H}$ than for $\delta^{18} \mathrm{O}$.

For $\delta^{2} \mathrm{H}$, Z-scores varied between 0.1 (computed between SPC and CVD-TwB for samples collected from a beech tree in Ressi) and 19.6 (computed between SPC and CVD-TwB for samples collected from an alder tree in Ahr/Aurino). The median Z-scores for $\delta^{2} \mathrm{H}$ were 6.0, 6.5, 6.6 and 7.6 computed between SPC with CVD-T, CVD-TwB, CVD-TcT and CVD$\mathrm{WC}$, respectively; these median values indicate that more than $50 \%$ of the Z-scores were above the limit for questionable differences $\left(Z\right.$-score $=5$ ) between the extraction methods (Fig. 8). For $\delta^{2} \mathrm{H}$, only few Z-scores (about $10 \%$ ) were lower than the upper limit for acceptable differences $\left(Z\right.$-score $=2$ ) between the methods. Overall, the smallest differences in $\delta^{2} \mathrm{H}$ (and Z-scores) were found between SPC and CVD-T, followed by SPC and CVD-TwB (Fig. 8).

For $\delta^{18} \mathrm{O}$, Z-scores varied between 0.1 (computed between SPC and CVD-T for samples collected from a beech tree in Ressi) and 46.6 (computed between SPC and CVD-T for samples collected from an alder tree in Ahr/Aurino). The median Z-scores for $\delta^{18} \mathrm{O}$ were 12.4, 10.8, 19.8 and 16.1 computed between SPC with CVD-T, CVD-TwB, CVD-TcT and CVD-WC, respectively; these median values indicate that about $75 \%$ of the Z-scores were above the limit for questionable differences 

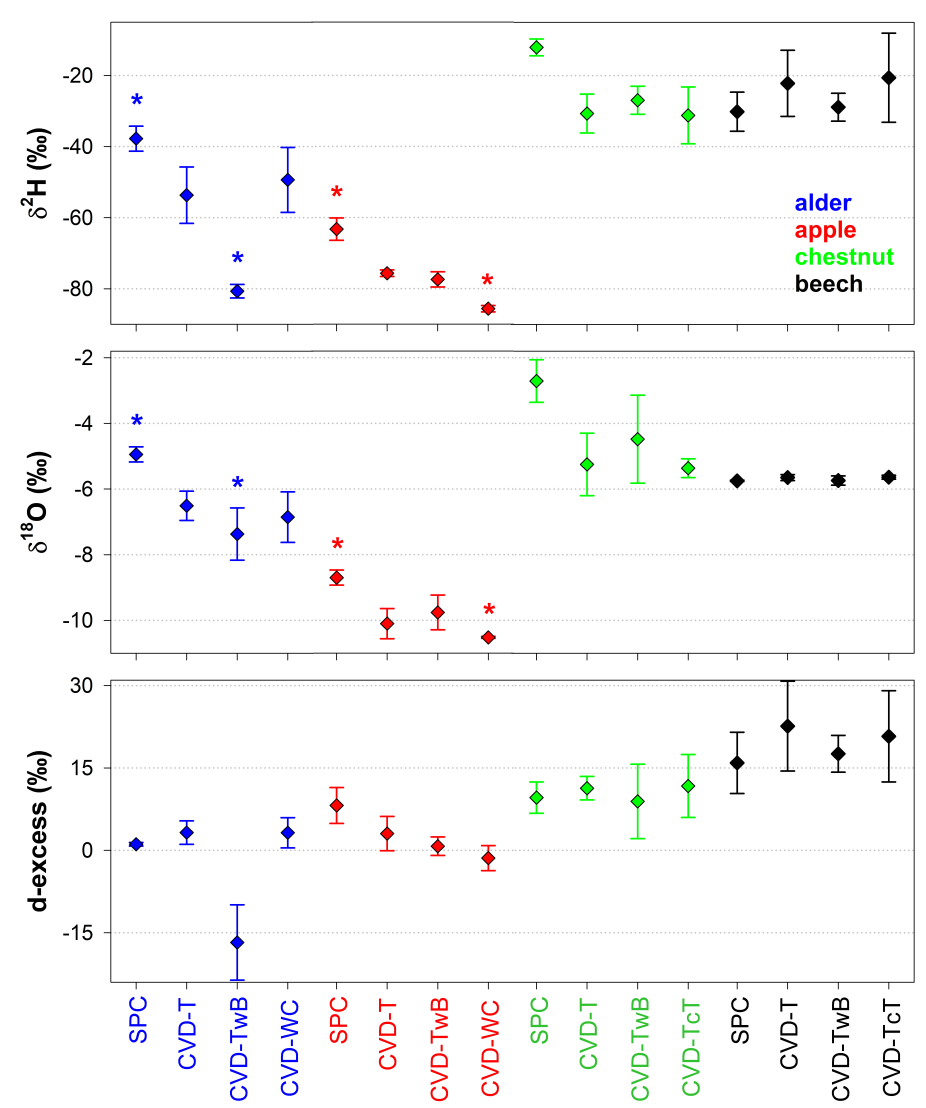

Figure 7. Median isotopic composition and d-excess of plant water extracted by SPC (i.e., Scholander-type pressure chamber) and CVD (i.e., cryogenic vacuum distillation), grouped by plant tissue and species. Error bars represent the median absolute deviations. Asterisks above the dots indicate significantly different groups $(\mathrm{p}<0.05$, multiple comparison test based on Tukey method, run after the Friedman repeated measures analysis of variance on ranks).

between the extraction methods (Fig. 8). For $\delta^{18} \mathrm{O}$, only few Z-scores (less than $10 \%$ ) were lower than the upper limit for acceptable differences between the methods. The smallest differences in $\delta^{18} \mathrm{O}$ (and Z-scores) were observed between SPC and CVD-TwB, followed by SPC and CVD-T (Fig. 8).

\section{Discussion}

\subsection{Advantages and limitations of water extraction by SPC}

The SPC has the advantage of extracting plant water that is likely used for transpiration and it is not tightly stored in the plant tissues (Meiri et al., 1975; Grossiord et al., 2017). The water extraction by SPC can be applied directly in situ or in a laboratory after a proper handling and transport of the vegetation material in sealed bags. The procedure for the extraction of plant water 

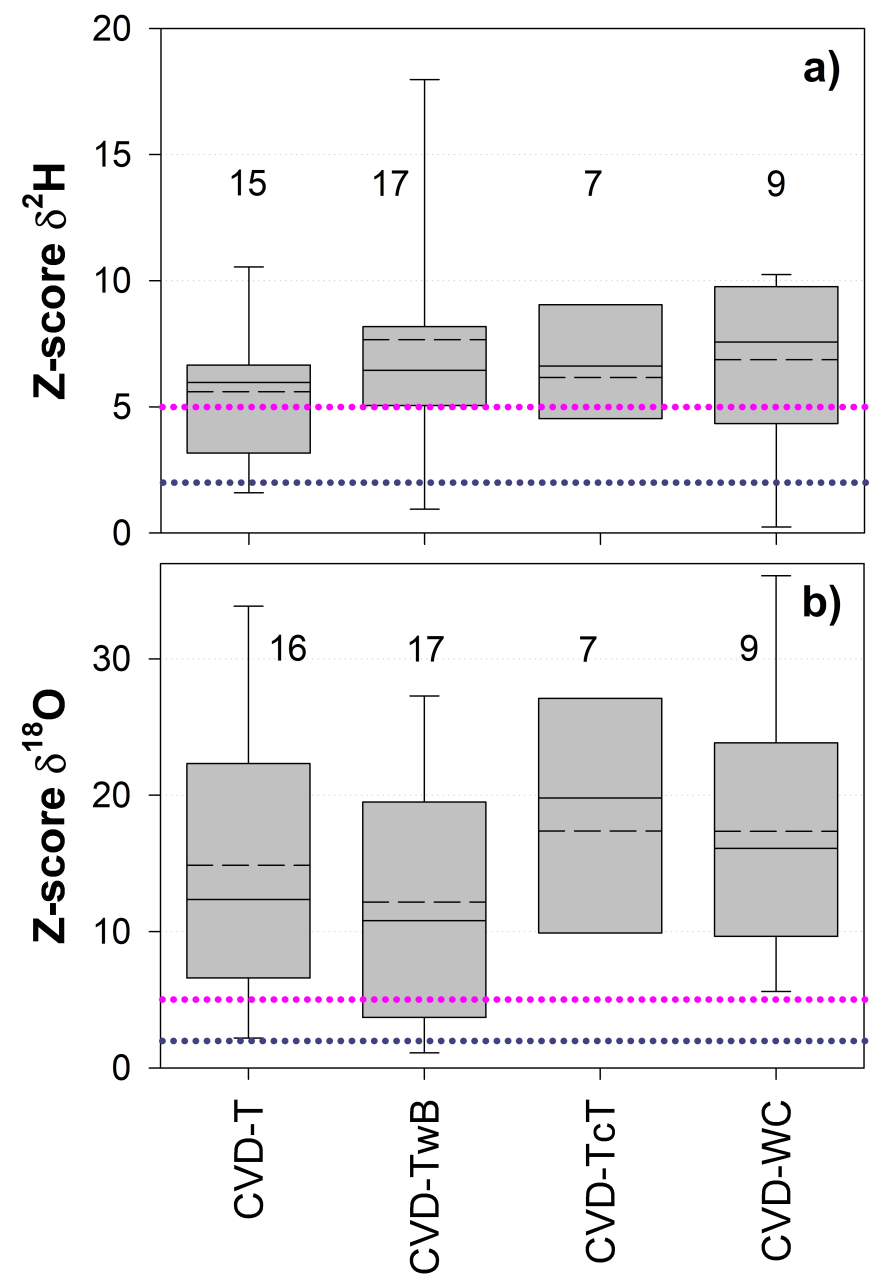

Figure 8. Dimensionless Z-score values for $\delta^{2} \mathrm{H}$ (a) and $\delta^{18} \mathrm{O}(\mathrm{b})$ grouped by sample types (CVD: cryogenic vacuum distillation; T: twig without bark; TwB: twig with bark; TcT: twig close to the trunk; WC: wood core). Samples from the four species were grouped together, and numbers above the boxes represent the sample size. The boxes indicate the $25^{\text {th }}$ and $75^{\text {th }}$ percentile, the whiskers indicate the $10^{t h}$ and $90^{t h}$ percentile, whereas the horizontal solid and dashed lines within the box mark the median and the mean, respectively. The dotted blue and pink lines represent the upper limits for acceptable $(Z$-score $=2)$ and questionable $(Z$-score $=5)$ differences, respectively, between the SPC (i.e., Scholander-type pressure chamber) and the CVD extracted samples. 
is also simple because it does not require specific laboratory work (such as, the handling of liquid nitrogen and the transfer of the sample in different vials), as for the CVD system. In addition, water extraction by SPC generally lasts few minutes depending on the shoot water potential, whereas the extraction by CVD could last from few minutes (15 min in this study) up to hours (Millar et al., 2018). The easy and fast application (without laboratory work) of the SPC for plant water extraction can be considered comparable to the simple and low-cost methods developed by Fischer et al. (2019).

Despite these advantages, our samplings showed that the water extraction by SPC is not always satisfactory in terms of sampling volume and extraction times (e.g., in the Ressi catchment during a dry period in July 2017 at the sunrise). For some shoot samples collected in Ressi, we had to apply a 3.0-MPa pressure for the extraction of at least $200 \mu 1$ for the isotopic analysis by IRMS, and the whole sample extraction lasted about $10 \mathrm{~min}$. The sampling procedure was also complicated by the extraction of few small water droplets and air bubbles that were difficult to trap into the vials. Conversely, the plant water extraction by CVD was performed for all the samples, and generally obtaining sampling volumes much larger than 200 $\mu$ l. Furthermore, plant water extracts obtained by SPC usually were darker (yellowish or even brownish) compared to water extracts by CVD. The dark colour of the SPC plant water extracts suggests a possibly large concentration in organic compounds (Millar et al., 2018), likely due to a partial destruction of plant cell walls. In our case, the sampling volume was not enough to quantify the concentration of organic compounds. Compared to this study, Gei $\beta$ ler et al. (2019) performed a post-processing analysis (by a spectral contamination identifier software) to quantify the spectral contamination of organic compounds, and found that for six stem water samples from Acacia mellifera shrubs, the relative degree of interference from contaminants was clearly higher for CVD than SPC extracted plant water (Fig. S1 in Gei $\beta$ ler et al. (2019)). Given that we were not able to quantify the concentration in organic compounds in our samples, and Gei $\beta$ ler et al. (2019) carried out a quantification of the spectral contamination for just six samples and only one plant species, we recommend that future inter-method studies should compare the isotopic composition of plant water extracted by SPC and CVD, as well as the measured concentration of organic compounds.

\subsection{Does the SPC water extraction represent an alternative to the CVD?}

Our results suggest that SPC can extract plant water in a simple and fast procedure that does not require laboratory work compared to other methods, such as CVD (Fischer et al., 2019; Geißler et al., 2019). However, some drawbacks, such as the small sampling volume that can be extracted during water deficit conditions, and the isotopic differences found with the plant water extracted by the widely-used CVD, indicate that the SPC and CVD methods cannot be considered as interchangeable plant water extractions.

Our inter-method comparison showed that the isotopic composition of the samples obtained by SPC, differently from the CVD-L ones, were not affected by fractionation (samples plotted close to the three LMWLs, Fig. 4), indicating that we did not extract significant volumes of plant water, which is subject to water-vapor exchanges with the low atmosphere. The d-excess values of plant water extracted by SPC and CVD were generally positive (except for CVD-L, and CVD-TwB samples collected from alder trees, Fig. 7), indicating no isotopic fractionation, with values even above 10 for plant water samples extracted from beech and some chestnut trees in Ressi. Despite the similarity in d-excess between samples extracted with the two methods 
(no significant differences were found by the Friedman repeated measures analysis of variance on ranks, p > 0.05, Fig. 7), we observed that plant water collected by CVD method from alder, apple and chestnut trees was always more depleted in heavy isotopes (both $\delta^{2} \mathrm{H}$ and $\delta^{18} \mathrm{O}$ ), and in some cases significantly different (i.e., comparison between SPC with CVD-TwB from alder trees and CVD-WC from apple trees, $\mathrm{p}<0.05$, Tukey test) from plant water samples extracted by SPC (Figs. 5, 6 and 7). These results are similar to those found by Millar et al. (2018) who reported a depletion in heavy isotopes for spring wheat (Triticum aestivum) samples derived by CVD compared to other techniques, such as direct vapor equilibration and microwave extraction. The water extracted by SPC and CVD showed differences in the isotopic composition among plant tissues, larger than the uncertainty in the isotopic measurements, and such differences were considered unacceptable in terms of Z-scores for more than $50 \%$ of the samples (even more than $75 \%$ when considering $\delta^{18} \mathrm{O}$, Fig. 8). These results are in contrast with those found by Gei $\beta$ ler et al. (2019), who reported a large variability in $\delta^{18} \mathrm{O}$, but no statistical differences for six stem water samples of Acacia mellifera extracted by CVD and SPC. However, we must consider that Gei $\beta$ ler et al. (2019) compared a limited number of samples and a different species.

In our study, we relate the observed isotopic differences between SPC and CVD samples to various factors, such as the possible effect of organic compounds on the isotopic composition of plant water (although we did not check this effect) or the sampling material (e.g., xylem water extracted at the shoot water potential by SPC vs. more-tightly bound water stored in plant cells and likely extracted by CVD). Millar et al. (2018) reported that different methods can extract different water pools within the plants, and CVD extracts up to $99 \%$ of the water in a sample, i.e. CVD accesses total plant water. Conversely, SPC only extracts water present in the xylem conduits, and given the much smaller sample volumes we collected by SPC than by $\mathrm{CVD}(\approx 200 \mu \mathrm{l}$ for SPC vs. $\approx 2 \mathrm{ml}$ for CVD), we likely extracted different plant water pools when using the two methods, with the former method pulling out more easily mobilized xylem water than water stored in living cells. In addition, we must consider that, while SPC likely extracts only water within the xylem (consisting of dead cells), CVD tends to retrieve all the water stored in the sampled tissues (including dead and living cells), which may have very different residence times (Millar et al., 2018). Water taken up by roots and transported in the xylem conduits can reach very rapidly the leaves and be available for transpiration, whereas the living cells (which are particularly abundant in the leaves and other non-lignified tissues) may store water taken up several days or even months before the sampling date. Therefore, water taken up by roots in different periods and stored in different tissues might have very different isotopic compositions, and this can mask the method comparison because that water can be retrieved by CVD, but not by SPC.

The ability of SPC and CVD to extract different plant water pools has implications for studies investigating the water sources exploited by plants for transpiration (e.g., Bowling et al., 2017; Barbeta et al., 2019; Amin et al., 2020). Indeed, significantly different isotopic compositions in the extracted plant water can complicate the identification of the water sources contributing to transpiration, and result in different estimations of the contributing water sources (Barbeta et al., 2019). In this view, such studies should rely more on methods extracting apoplastic water from transpiring trees (like SPC) than on methods extracting, in addition to xylem water, also other plant water fractions (stored in living cells) that are likely much older than the actual xylem water (Zhang et al., 2017; Millar et al., 2018). 
Furthermore, our results show that the differences in the isotopic composition between SPC and CVD vary not only based on the plant tissue used for CVD, but also based on the plant species (differences were more marked for alder, apple and chestnut tree than for beech tree samples). Given the isotopic differences among various species and the results obtained by Gei $\beta$ ler et al. (2019), more research is needed to compare multiple extraction methods (SPC should not only be compared to CVD, but as well as to direct vapor equilibration, microwave extraction, centrifugation etc.), across various environments and plant species, to investigate the technical and physical factors altering the isotopic composition of plant water during the extraction, and elaborate standard protocols for ecohydrological research relying on the isotopic signature of plant water.

\section{Concluding remarks}

Recent studies highlighted problems associated to the reliability of plant water extraction methods for isotopic analyses, mainly because different methods do not extract the same water pool in the plant tissues, and some of them can extract large concentrations of organic compounds, potentially affecting the isotopic analysis. In this work, we analyzed the variability in the isotopic composition of plant water extracted by cryogenic vacuum distillation (CVD) and Scholander-type pressure chamber (SPC), also considering the potential variability in the isotopic signature of the plant tissues (i.e., leaves, twig without bark, twig with bark, twig close to the trunk of the tree, and wood core) and plant species (i.e., alder, apple, chestnut and beech trees). The procedure for the extraction of plant water by SPC is simple, can be carried out in situ, and it does not require specific laboratory work as in case of CVD. However, the main limitation of SPC is the very small water volume that can be extracted from the lignified shoot during water deficit conditions (and high transpiration moments), compared to CVD. Moreover, our results indicated that the isotopic composition of plant water extracted by SPC and CVD was significantly different. While SPC and most of the CVD samples (except for CVD applied to leaves) did not exhibit an evaporative signature, there was a large isotopic variability among the samples. We found that, for beech tree samples, the difference in both $\delta^{2} \mathrm{H}$ and $\delta^{18} \mathrm{O}$ obtained by the two extraction methods was smaller compared to the difference observed for alder, apple and chestnut tree samples. Specifically, the isotopic composition of alder, apple and chestnut plant water extracted by SPC was enriched in heavy isotopes compared to samples obtained by CVD applied to twigs or wood cores. Based on these results, we conclude that plant water extraction by SPC is not an alternative to CVD, as SPC likely extracts only xylem water (which was theoretically recently taken up by roots and is easily available for transpiration), whereas CVD tends to retrieve total plant water (likely stored both in dead and living cells) from the samples. Therefore, studies aiming to quantify the relative contribution of the water sources to transpiration should rely more on the isotopic composition of xylem water transpiring at the moment of the sampling or during the sampling day (which is theoretically sampled by SPC), than the isotopic composition of total plant water (sampled by CVD), which also contains a fraction of water that could be stored in plant tissues for long time. Based on our findings, we call for future research investigating the same methods across more plant species, and quantifying the organic compounds in both SPC and CVD samples to determine the effect on the isotopic composition of plant water. 
https://doi.org/10.5194/hess-2020-446

Preprint. Discussion started: 16 October 2020

(c) Author(s) 2020. CC BY 4.0 License.

(c) (P)
Hydrology and

Earth System

Sciences

Discussions

Data availability. Data are available from the corresponding author upon reasonable request.

Author contributions. DP conceptualized the methodological comparison between the two methods. JF, GZ and ME designed the research. $\mathrm{JF}$ and ME collected field data in the Ahr/Aurino and Laas/Lasa sites, whereas CM, GZ and AA carried out the field campaigns in the

375 Ressi catchment. JF and AA performed the plant water extraction by the cryogenic vacuum distillation. FS and DZ provided support for the sampling in Laas/Lasa and the laboratory activities. VC and TA provided technical support and comments for the plant water extraction by the Scholander-type pressure chamber. GZ analyzed the data set, and prepared the first draft of the manuscript with contributions from AA, JF, ME and CM. All the authors contributed to the editing of the manuscript. FC, MB and MT funded the research.

Competing interests. The authors declare that they have no conflict of interest.

Acknowledgements. GZ and CM acknowledge the financial support provided by Fondazione Cassa di Risparmio di Padova e Rovigo (Italy) (research project "Ecohydrological Dynamics and Water Pathways in Forested Catchments", Bando Starting Grants 2015). Research in the Ressi catchment was also supported by the Italian MIUR Project (PRIN 2017) "WATer mixing in the critical ZONe: observations and predictions under environmental changes-WATZON" (national coordinator: Marco Borga). Research in the Ahr/Aurino study area was supported by the RIVERMOOD project funded by the Free University of Bozen-Bolzano (Italy). Research in the Laas/Lasa study site was supported by the project "Parco Tecnologico-Tecnologie Ambientali" of the Autonomous Province of Bozen-Bolzano (Italy).

The authors would like to thank Christian Ceccon for the isotopic analyses and the support during the laboratory activities at the Free University of Bozen-Bolzano (Italy). 


\section{References}

Allen, S.T., Kirchner, J.W., Braun, S., Siegwolf, R.T.W., and Goldsmith, G.R.: Seasonal origins of soil water used by trees, Hydrol. Earth Syst. Sci., 23, 1199-1210, https://doi.org/10.5194/hess-23-1199-2019, 2019.

Amin, A., Zuecco, G., Geris, J., Schwendenmann, L., McDonnell, J.J., Borga, M., and Penna, D.: Depth distribution of soil water sourced by plants at the global scale: a new direct inference approach, Ecohydrology, 13, e2177, https://doi.org/10.1002/eco.2177, 2020.

Barbeta, A., Jones, S.P., Clavé, L., Wingate, L., Gimeno, T.E., Fréjaville, B., Wohl, S., and Ogée, J.: Unexplained hydrogen isotope offsets complicate the identification and quantification of tree water sources in a riparian forest, Hydrol. Earth Syst. Sci., 23, 2129-2146, https://doi.org/10.5194/hess-23-2129-2019, 2019.

Böttcher, G., Brumsack, H., Heinrichs, H., and Pohlmann, M.: A new high pressure squeezing technique for pore fluid extraction from terrestrial soils, Water Air Soil Pollut., 94, 289-296, https://doi.org/10.1007/BF02406064, 1997.

Bowling, D.R., Schulze, E.S., and Hall, S.J.: Revisiting streamside trees that do not use stream water: can the two water worlds hypothesis and snowpack isotopic effects explain a missing water source?, Ecohydrology, 10(1), e1771, https://doi.org/10.1002/eco.1771, 2017.

Boyer, J.S.: Leaf water potentials measured with a pressure chamber, Plant Physiol., 42(1), 133-137, https://doi.org/10.1104/pp.42.1.133, 1967.

Brooks, R.J., Barnard, H.R., Coulombe, R., and McDonnell, J.J.: Ecohydrologic separation of water between trees and streams in a Mediterranean climate, Nat. Geosci., 3, 100-104, https://doi.org/10.1038/ngeo722, 2010.

Campana, D., Marchese, E., Theule, J.I., and Comiti, F.: Channel degradation and restoration of an Alpine river and related morphological changes, Geomorphology, 221, 230-241, https://doi.org/10.1016/j.geomorph.2014.06.016, 2014.

Castro Neto, M.T., Reinhardt, D.H., and da S. Ledo, C.A.: Determination of water potential on mango trees by pressure chamber, Acta Hortic., 645, 425-427, https://doi.org/10.17660/ActaHortic.2004.645.53, 2004.

Cochard, H., Forestier, S., and Améglio, T.: A new validation of the Scholander pressure chamber technique based on stem diameter variations, J. Exp. Bot., 52(359), 1361-1365, https://doi.org/10.1093/jxb/52.359.1361, 2001.

410 Craig, H.: Isotopic variations in meteoric waters, Science, 133(3465), 1702-1703, https://doi.org/10.1126/science.133.3465.1702, 1961.

Dansgaard, W.: The abundance of $\mathrm{O}^{18}$ in atmospheric water and water vapour, Tellus, 5(4), 461-469, https://doi.org/10.1111/j.21533490.1953.tb01076.x, 1953.

Dansgaard, W.: Stable isotopes in precipitation, Tellus, 16, 436-468, https://doi.org/10.3402/tellusa.v16i4.8993, 1964.

Donovan, L.A., Richards, J.H., and Linton, M.J.: Magnitude and mechanisms of disequilibrium between predawn plant and soil water potentials, Ecology, 84(2), 463-470, https://doi.org/10.1890/0012-9658(2003)084[0463:MAMODB]2.0.CO;2, 2003.

Dubbert, M., Caldeira, M.C., Dubbert, D., and Werner, C.: A pool-weighted perspective on the two-water-worlds hypothesis, New Phytol., 222, 1271-1283, https://doi.org/10.1111/nph.15670, 2019.

Engel, M., Penna, D., Frentress, J., Andreoli, A., Hecher, P., van Meerveld, H.J., and Comiti, F.: Controls on ecohydrological dynamics of riparian zones in Alpine catchments: A comparison study of two rivers in the Eastern Italian Alps., in review.

Fischer, B.M.C., Frentress, J., Manzoni, S., Cousins, S.A.O., Hugelius, G., Greger, M., Smittenberg, R.H., and Lyon, S.W.: Mojito, anyone? An exploration of low-tech plant water extraction methods for isotopic analysis using locally-sourced materials, Front. Earth Sci., 7, 150, https://doi.org/10.3389/feart.2019.00150, 2019.

Geißler, K., Heblack, J., Uugulu, S., Wanke, H., and Blaum, N.: Partitioning of water between differently sized shrubs and potential groundwater recharge in a semiarid savanna in Namibia, Front. Plant Sci., 10, 1411, https://doi.org/10.3389/fpls.2019.01411, 2019. 

McDowell, N.G.: Precipitation, not air temperature, drives functional responses of trees in semi-arid ecosystems, J. Ecol., 105, 163-175, https://doi.org/10.1111/1365-2745.12662, 2017.

Kerstel, E.R.T., van Trigt, R., Reuss, J., and Meijer, H.A.J.: Simultaneous determination of the ${ }^{2} \mathrm{H} /{ }^{1} \mathrm{H},{ }^{17} \mathrm{O} /{ }^{16} \mathrm{O}$, and ${ }^{18} \mathrm{O} /{ }^{16} \mathrm{O}$ isotope abundance ratios in water by means of laser spectrometry, Anal. Chem., 71, 5297-5303, https://doi.org/10.1021/ac990621e, 1999.

Klaus, J., and McDonnell, J.J.: Hydrograph separation using stable isotopes: Review and evaluation, J. Hydrol., 505, 47-64, https://doi.org/10.1016/j.jhydrol.2013.09.006, 2013.

Koeniger, P., Marshall, J. D., Link, T., and Mulch, A.: An inexpensive, fast, and reliable method for vacuum extraction of soil and plant water for stable isotope analyses by mass spectrometry, Rapid Commun. Mass Spectrom., 25(20), 3041-3048, https://doi.org/10.1002/rcm.5198, 2011.

Landwehr, J.M., and Coplen, T.B.: Line-conditioned excess: A new method for characterizing stable hydrogen and oxygen isotope ratios in hydrologic systems, In International Conference on Isotopes in Environmental Studies, 132-135, IAEA Vienna, 2004.

Liu, J., Shen, L., Wang, Z., Duan, S., Wu, W., Peng, X., Wu, C., and Jiang, Y.: Response of plants water uptake patterns to tunnels excavation based on stable isotopes in a karst trough valley, J. Hydrol., 571, 485-493, https://doi.org/10.1016/j.jhydrol.2019.01.073, 2019a.

Liu, Y., Zhang, X., Zhao, S., Ma, H., Qi, G., and Guo, S.: The depth of water taken up by walnut trees during different phenological stages in an irrigated arid hilly area in the Taihang Mountains, Forests, 10(2), 121, https://doi.org/10.3390/f10020121, 2019b.

Marchina, C., Zuecco, G., Chiogna, G., Bianchini, G., Carturan, L., Comiti, F., Engel, M., Natali, C., Borga, M., and Penna, D.: Alternative methods to determine the $\delta^{2} \mathrm{H}-\delta^{18} \mathrm{O}$ relationship: an application to different water types, J. Hydrol., 587, 124951, https://doi.org/10.1016/j.jhydrol.2020.124951, 2020.

McDonnell, J.J.: The two water worlds hypothesis: ecohydrological separation of water between streams and trees?, WIREs Water, 1, 323329, https://doi.org/10.1002/wat2.1027, 2014.

Meiri, A., Plaut, Z., and Shimshi, D.: The use of the pressure chamber technique for measurement of the water potential of transpiring plant organs, Physiol. Plantarum, 35(1), 72-76, https://doi.org/10.1111/j.1399-3054.1975.tb03870.x, 1975.

Millar, C., Pratt, D., Schneider, D.J., and McDonnell, J.J.: A comparison of extraction systems for plant water stable isotope analysis, Rapid Commun. Mass Spectrom., 32, 1031-1044, https://doi.org/10.1002/rcm.8136, 2018.

Munksgaard, N.C., Cheesman, A.W., Wurster, C.M., Cernusak, L.A., and Bird, M.I.: Microwave extraction-isotope ratio infrared spectroscopy (MEIRIS): a novel technique for rapid extraction and in-line analysis of $\delta 18 \mathrm{O}$ and $\delta 2 \mathrm{H}$ values of water in plants, soils and insects, Rapid Commun Mass Spectrom., 28(20), 2151-2161, https://doi.org/10.1002/rcm.7005, 2014.

Oerter, E.J., Siebert, G., Bowling, D.R., and Bowen, G.: Soil water vapour isotopes identify missing water source for streamside trees, Ecohydrology, 12(4), e2083, https://doi.org/10.1002/eco.2083, 2019.

Orlowski, N., Breuer, L., Angeli, N., Boeckx, P., Brumbt, C., Cook, C.S., Dubbert, M., Dyckmans, J., Gallagher, B., Gralher, B., Herbstritt, B., Hervé-Fernández, P., Hissler, C., Koeniger, P., Legout, A., Macdonald, C.J., Oyarzún, C., Redelstein, R., Seidler, C., Siegwolf, R., Stumpp, C., Thomsen, S., Weiler, M., Werner, C., and McDonnell, J.J.: Inter-laboratory comparison of cryogenic water extraction systems for stable isotope analysis of soil water, Hydrol. Earth Syst. Sci., 22, 3619-3637, https://doi.org/10.5194/hess-22-3619-2018, 2018.

Orlowski, N., Breuer, L., and McDonnell, J.J.: Ecohydrology Bearings - Invited Commentary Critical issues with cryogenic extraction of soil water for stable isotope analysis, Ecohydrology, 9, 3-10, https://doi.org/10.1002/eco.1722, 2016a.

Orlowski, N., Frede, H.-G., Brüggemann, N., and Breuer, L.: Validation and application of a cryogenic vacuum extraction system for soil and plant water extraction for isotope analysis, J. Sens. Sens. Syst., 2, 179-193, https://doi.org/10.5194/jsss-2-179-2013, 2013. 
Orlowski, N., Pratt, D.L., and McDonnell, J.J.: Intercomparison of soil pore water extraction methods for stable isotope analysis, Hydrol. Process., 30(19), 3434-3449, https://doi.org/10.1002/hyp.10870, 2016b.

Penna, D., Geris, J., Hopp, L., and Scandellari, F.: Water sources for root water uptake: Using stable isotopes of hydrogen and oxygen as a research tool in agricultural and agroforestry systems, Agr. Ecosyst. Environ., 291, 106790, https://doi.org/10.1016/j.agee.2019.106790, 2020.

Penna, D., Hopp, L., Scandellari, F., Allen, S.T., Benettin, P., Beyer, M., Geris, J., Klaus, J., Marshall, J.D., Schwendenmann, L., Volkmann, T.H.M., von Freyberg, J., Amin, A., Ceperley, N., Engel, M., Frentress, J., Giambastiani, Y., McDonnell, J.J., Zuecco, G., Llorens, P., Siegwolf, R.T.W., Dawson, T.E., and Kirchner, J.W.: Ideas and perspectives: Tracing terrestrial ecosystem water fluxes using hydrogen and oxygen stable isotopes - challenges and opportunities from an interdisciplinary perspective, Biogeosciences, 15, 6399-6415, https://doi.org/10.5194/bg-15-6399-2018, 2018.

Penna, D., van Meerveld, H.J., Oliviero, O., Zuecco, G., Assendelft, R.S., Dalla Fontana, G., and Borga, M.: Seasonal changes in runoff generation in a small forested mountain catchment, Hydrol. Process., 29(8), 2027-2042, https://doi.org/10.1002/hyp.10347, 2015.

Penna, D., Oliviero, O., Assendelft, R., Zuecco, G., van Meerveld, I., Anfodillo, T., Carraro, V., Borga, M., and Dalla Fontana, G.: Tracing the water sources of trees and streams: isotopic analysis in a small pre-alpine catchment, Procedia Environ. Sci., 19, 106-112. https://doi.org/10.1016/j.proenv.2013.06.012, 2013.

Penna, D., Stenni, B., Šanda, M., Wrede, S., Bogaard, T.A., Gobbi, A., Borga, M., Fischer, B.M.C., Bonazza, M., and Chárová, Z.: On the reproducibility and repeatability of laser absorption spectroscopy measurements for $\delta^{2} \mathrm{H}$ and $\delta^{18} \mathrm{O}$ isotopic analysis, Hydrol. Earth Syst. Sci., 14, 1551-1566, https://doi.org/10.5194/hess-14-1551-2010, 2010.

Peters, L.I., and Yakir, D.: A direct and rapid leaf water extraction method for isotopic analysis, Rapid Commun. Mass Spectrom., 22(18), 2929-2936, https://doi.org/10.1002/rcm.3692, 2008.

Qiu, X., Zhang, M., Wang, S., Evaristo, J., Argiriou, A.A., Guo, R., Chen, R., Meng, H., Che, C., and Qu, D.: The test of the ecohydrological separation hypothesis in a dry zone of the northeastern Tibetan Plateau, Ecohydrology, 12(3), e2077, https://doi.org/10.1002/eco.2077, 2019.

Quade, M., Klosterhalfen, A., Graf, A., Brüggemann, N., Hermes, N., Vereecken, H., and Rothfuss, Y.: In-situ monitoring of soil water isotopic composition for partitioning of evapotranspiration during one growing season of sugar beet (Beta vulgaris), Agr. Forest Meteorol., 266-267, 53-64, https://doi.org/10.1016/j.agrformet.2018.12.002, 2019.

Scheff, S.W.: Fundamental statistical principles for the neurobiologist: A survival guide, Academic Press, pp. 234, https://doi.org/10.1016/C2015-0-02471-6, 2016.

Scholander, P.F., Bradstreet, E.D., Hemmingsen, E.A., and Hammel, H.T.: Sap pressure in vascular plants, Science, 148(3668), 339-346, https://doi.org/10.1126/science.148.3668.339, 1965.

Sprenger, M., Herbstritt, B., and Weiler, M.: Established methods and new opportunities for pore water stable isotope analysis, Hydrol. Process., 29(25), 5174-5192, https://doi.org/10.1002/hyp.10643, 2015.

495 Turner, N.C.: Technique and experimental approaches for the measurement of plant water status, Plant Soil, 58, 339-366, https://doi.org/10.1007/BF02180062, 1981.

Volkmann, T.H.M., Kühnhammer, K., Herbstritt, B., Gessler, A., and Weiler, M.: A method for in situ monitoring of the isotope composition of tree xylem water using laser spectroscopy, Plant Cell Environ., 39(9), 2055-2063, https://doi.org/10.1111/pce.12725, 2016.

von Freyberg, J., Studer, B., and Kirchner, J.W.: A lab in the field: high-frequency analysis of water quality and stable isotopes in stream water and precipitation, Hydrol. Earth Syst. Sci., 21, 1721-1739, https://doi.org/10.5194/hess-21-1721-2017, 2017. 
https://doi.org/10.5194/hess-2020-446

Preprint. Discussion started: 16 October 2020

(c) Author(s) 2020. CC BY 4.0 License.

Wassenaar, L.I., Ahmad, M., Aggarwal, P., van Duren, M., Pöltenstein, L., Araguas, L., and Kurttas, T.: Worldwide proficiency test for routine analysis of $\delta^{2} \mathrm{H}$ and $\delta^{18} \mathrm{O}$ in water by isotope-ratio mass spectrometry and laser absorption spectroscopy, Rapid Commun. Mass Spectrom., 26(15), 1641-1648, https://doi.org/10.1002/rcm.6270., 2012.

Zhang, Z.Q., Evaristo, J., Li, Z., Si, B.C., and McDonnell, J.J.: Tritium analysis shows apple trees may be transpiring water several decades old, Hydrol. Process., 31, 1196-1201, https://doi.org/10.1002/hyp.11108, 2017.

Zhang, Z., Yu, K., Siddique, K.H.M., and Nan, Z.: Phenology and sowing time affect water use in four warm-season annual grasses under a semi-arid environment, Agr. Forest Meteorol., 269-270, 257-269, https://doi.org/10.1016/j.agrformet.2019.02.027, 2019.

Zuecco, G., Penna, D., Borga, M., and van Meerveld, H.J.: A versatile index to characterize hysteresis between hydrological variables at the runoff event timescale, Hydrol. Process., 30(9), 1449-1466, https://doi.org/10.1002/hyp.10681, 2016.

510 Zuecco, G., Penna, D., van Meerveld, H.J., Hopp, L., Dalla Fontana, G., and Borga, M.: Comparison of two different types of throughfall collectors, Die Bodenkultur, 65 (3-4), 51-56, 2014. 